\title{
Evaluation of High-Performance Asphalt Binders Modified with SBS, SIS, and GTR
}

\author{
Hyun Hwan Kim, ${ }^{1}$ Mithil Mazumder, ${ }^{1}$ Moon-Sup Lee $\mathbb{D}^{,}{ }^{2}$ and Soon-Jae Lee $\mathbb{D}^{1}$ \\ ${ }^{1}$ Texas State University, San Marcos, TX 78666, USA \\ ${ }^{2}$ Korea Institute of Civil Engineering and Building Technology, Goyang, Gyeonggi 10223, Republic of Korea \\ Correspondence should be addressed to Moon-Sup Lee; truepath@kict.re.kr
}

Received 6 May 2019; Revised 2 July 2019; Accepted 13 September 2019; Published 3 October 2019

Academic Editor: Claudio Mazzotti

Copyright (c) 2019 Hyun Hwan Kim et al. This is an open access article distributed under the Creative Commons Attribution License, which permits unrestricted use, distribution, and reproduction in any medium, provided the original work is properly cited.

\begin{abstract}
In this study, performance properties of polymer-modified asphalt (PMA) binders are evaluated depending on ground tire rubber (GTR) and styrene-isoprene-styrene (SIS). Styrene-butadiene-styrene- (SBS-) modified asphalt binder of PG 76-22 is used as a base binder to manufacture the rubberized PMA binder. The rubberized PMA binders are blended using SIS modifier. The binders were artificially short-term and long-term aged using rolling thin-film oven (RTFO) and pressure aging vessel (PAV) procedures. Superpave binder tests were conducted on the binders through rotational viscometer (RV), dynamic shear rheometer (DSR), and bending beam rheometer (BBR). Furthermore, multiple stress creep recovery (MSCR) test and atomic force microscopy (AFM) microstructural analysis were performed. The results of this study indicated that (1) the viscosity properties seem to be highly dependent on GTR and SIS contents, (2) the addition of SIS is observed to have a significant effect on improving the rutting performances of rubberized PMA binders, (3) the cracking properties are considered to be improved significantly through SIS modification, and (4) in general, the rubberized PMA binders with SIS showed the best performance for rutting and cracking among all the binders used in this study.
\end{abstract}

\section{Introduction}

Asphalt pavements are getting exposed to more extreme traffic conditions such as higher traffic volume and heavier loads. Increasingly, it is required to develop superior pavement materials that are less susceptible to rutting and cracking. A lot of polymers are usually utilized to improve crude asphalt binder, and a few examples are as follows: lowdensity polyethylene (LDPE), high-density polyethylene (HDPE), styrene-butadiene-styrene (SBS), ethylene-vinyl acetate (EVA), styrene-butadiene random copolymers (SBR), ethylene propylene diene monomers (EPDM), ground tire rubber (GTR), and styrene-isoprene-styrene (SIS).

SBS is one of the most common materials which produce high-quality polymer-modified asphalt (PMA) binder [1]. SBS-modified binder is known to be durable pavement material which has improved bonding strength with aggregate based on a three-dimensional network [2]. The formation of the network improves not only rutting resistance but also cracking resistance at low temperature by microdamage accumulation [3].

Generally, the huge amount of scrap tires (approximately 40 million of tires) is disposed on landfills in the United States [4]. GTR was recycled as a valuable asphalt modifier and was applied in pavement industry. Addition of GTR improves the rutting property due to increased stiffness and elasticity at a high temperature. Also, it extends the fatigue life of mixture through enhanced asphalt film which coated the aggregate in the mixture $[5,6]$. GTR modification takes a significant role in upgrading the asphalt binder through reduced stiffness at a low temperature, decreased traffic noise, and reduced maintenance costs [7-16]. Meanwhile, the effect of incorporation of GTR and SBS has been evaluated in the previous research [17]. The modified binders showed enhanced performances for both high- and low-temperature rheological properties. 
Even if the incorporation of two modifiers was effective, it is necessary to apply additional material to maximize the effect of modification. According to the previous research [18], the molecule chain of isoprene in SIS increases the complex modulus at high temperature, and due to its branch methyl in the isoprene group, it has better tenacity and compatibility with other materials. The dispersion of SIS in the asphalt binder is homogeneous like SBS-modified binder, although it needs specific temperature control and mixing time. The polymers completely dispersed in the asphalt binder showed a change in the molecular structure of the asphalt binder [19]. However, the dispersion of GTR represents a different mechanism that maintains the physical form and behaves in the binder producing a nonhomogeneous nature in modified binder.

The purpose of this study is to evaluate the PMA binders containing SBS, SIS, and GTR modifiers. The binders were aged through the RTFO and PAV procedures. Superpave binder tests were conducted to characterize at three aging states (original, short-term aging, and long-term aging). Furthermore, the multiple stress creep recovery (MSCR) test was applied to more effectively evaluate the rutting property of the rubberized PMA binder. Figure 1 shows a flowchart of the experimental design.

\section{Experimental Design}

2.1. Materials. SBS-modified binder of PG 76-22 was used as a base binder for this study. Table 1 shows the binder properties. The SIS modifier is shown in Figure 2. SIS contains the isoprene (2-methyl-1,3-butadiene; $\mathrm{C}_{5} \mathrm{H}_{8}$ ) which is produced by many plants and animals. Its polymers are the main component of natural rubber. Therefore, the addition of SIS is expected to result in higher aging resistance and good blend stability and improve elastic response, superior cohesion, tensile strength, and low-temperature flexibility. The SIS of $5 \%$ by weight of the binder was added and mixed with PG 76-22 binder. The mixing conditions were as follows: $177^{\circ} \mathrm{C}$ for 60 minutes by an open blade mixer at $700 \mathrm{rpm}$.

Rubberized PMA binders were manufactured using surface-treated GTR. Table 2 shows the gradation of GTR. The percentages of GTR were 5\% and $10 \%$ by weight of the base binder. The wet process was applied to produce rubberized PMA binder in the laboratory at $177^{\circ} \mathrm{C}$ for 30 minutes at a blending speed of $700 \mathrm{rpm}$. The consistency of the rubberized PMA binder was maintained using only one batch of GTR during the study.

2.2. Superpave Binder Tests. Superpave asphalt binder tests are used to measure asphalt's performance at three stages of its life: in its original state, after mixing and construction, and after in-service aging. In this study, the selected binder test procedures included the viscosity test (AASHTO T 316), the dynamic shear rheometer (DSR) test (AASHTO T 315), and the bending beam rheometer (BBR) test (AASHTOT 313). Three replicate samples were tested, and the results were reported as the average of these tests. A $10.5 \mathrm{~g}$ sample of binders was tested with a number 27 spindle in the Brookfield rotational viscometer at $135^{\circ} \mathrm{C}$ and $180^{\circ} \mathrm{C}$. In the DSR test, the binders (original, RTFO residual, and $\mathrm{RTFO}+\mathrm{PAV}$ residual) were tested at a frequency of 10 radians per second which is equal to approximately $1.59 \mathrm{~Hz}$. Each asphalt binder in both the original state (unaged) and short-term aged state is used to determine the $G^{*} / \sin \delta$. The $G^{*} \sin \delta$ at intermediate temperature was measured to evaluate the fatigue cracking property for RTFO+PAV residual binders. The BBR test was conducted on asphalt beams $(125 \times 6.35 \times 12.7 \mathrm{~mm})$ at $-12^{\circ} \mathrm{C}$, and the creep stiffness $(S)$ of the binder was measured at a loading time of $60 \mathrm{~s}$. A constant load of $100 \mathrm{~g}$ was then applied to the beam of the binder, which was supported at both ends, and the deflection of the center point was measured continuously. Testing was performed on the long-term aged state (RTFO + PAV residual samples).

2.3. Multiple Stress Creep Recovery (MSCR) Tests. DSR equipment is used to conduct MSCR test for the rubberized PMA binders. The test is conducted according to AASHTO TP 70 specification at $76^{\circ} \mathrm{C}$. All binders were tested in the short-term aged state. The samples are tested in creep and recovery at two stress levels: $0.1 \mathrm{kPa}$ and $3.2 \mathrm{kPa}$. Two parameters are derived from analyzing the MSCR test, i.e., the nonrecoverable creep compliance $\left(J_{\mathrm{nr}}\right)$ and percent recovery (\%rec). As shown in Figure 3, the binder is subjected to creep loading and unloading cycle of $1 \mathrm{sec}$ and $9 \mathrm{sec}$, respectively, at stress levels of $0.1 \mathrm{kPa}$ and $3.2 \mathrm{kPa}$, and ten cycles of loading are applied at each stress level. The output of the MSCR test is used to calculate nonrecoverable creep compliance $\left(J_{\mathrm{nr}}\right)$ and percent recovery (\%rec) for quantifying the rutting susceptibility of asphalt binders. The nonrecoverable creep compliance $\left(J_{\mathrm{nr}}\right)$, which is determined by dividing nonrecoverable shear strain by the shear stress, is used to evaluate the rutting potential of the asphalt binder.

2.4. Microstructural Analysis Using AFM. A Model 840-002380 Bruker Dimension Icon AFM (Bruker Instrument Inc.) is used to characterize the micromorphology of rubberized PMA binders with or without SIS through the surface images obtained from the prepared sample. Topographical and phase images of long-term aged binders are captured. Figure 4 shows the AFM equipment.

Topographical and phase images can be obtained with the scan speed of $0.498 \mathrm{~Hz}$ and the scan size of $20 \mu \mathrm{m} \times 20 \mu \mathrm{m}$. Topographical images represent the terrain of the surface. Phase images are displayed with a sharp resolution that can be intercepted by the surface roughness of the terrain image captured by the AFM height mode. The colors of the phase images define various mechanical properties of the phases, as obtained from sample-tip interactions, and could be related to different viscoelastic properties or adhesive force.

2.5. Statistical Analysis Method. Statistical analysis was performed using the Statistical Analysis System (SAS) 


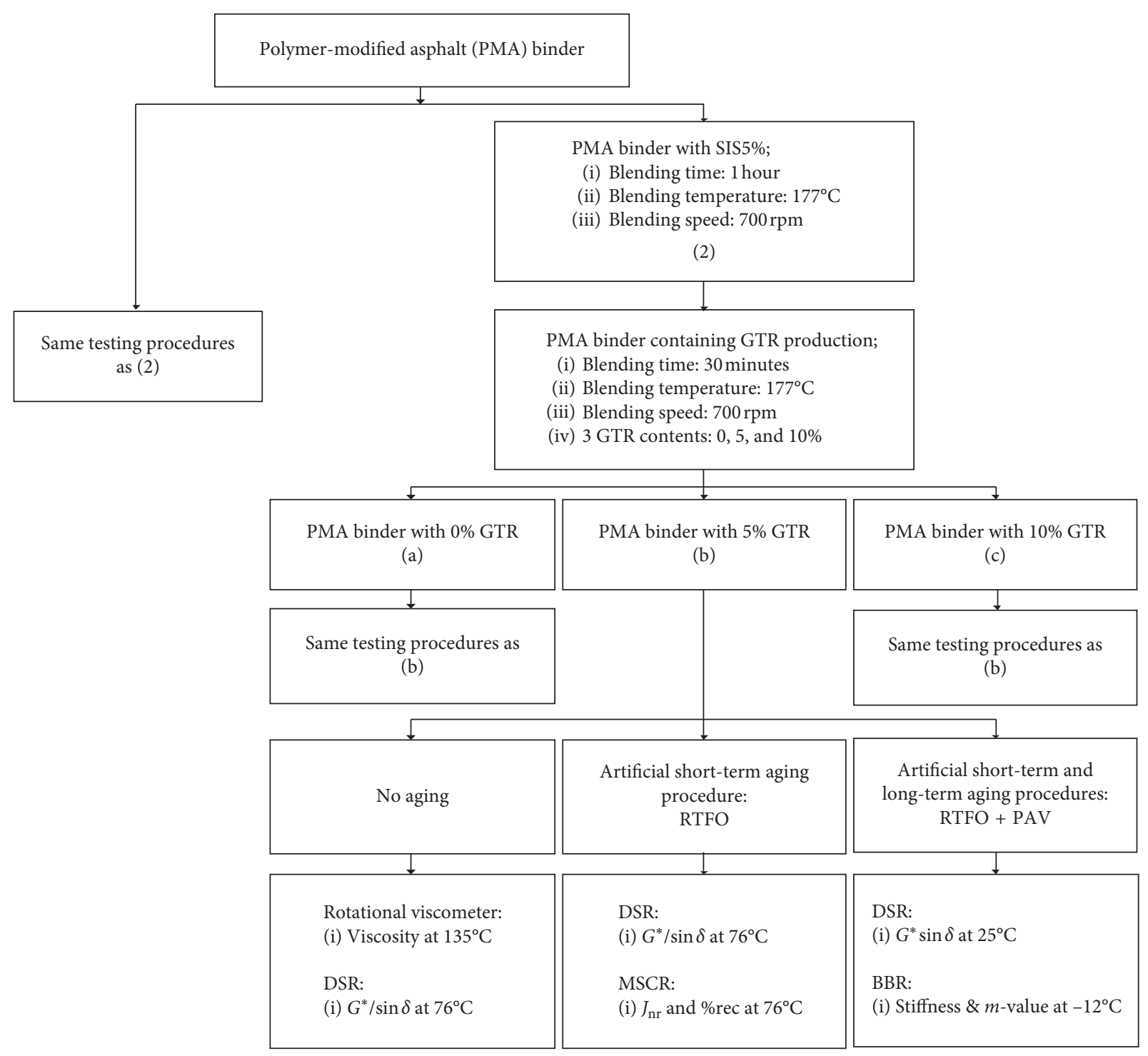

FIGURE 1: Flowchart of experimental design procedures.

TABle 1: Properties of base asphalt binder (PG 76-22).

\begin{tabular}{lcc}
\hline Aging states & Test properties & Test result \\
\hline \multirow{2}{*}{ Unaged binder } & Viscosity at $135^{\circ} \mathrm{C}(\mathrm{Pa}-\mathrm{s})$ & 3.244 \\
& $G^{*} / \sin \delta$ at $76^{\circ} \mathrm{C}(\mathrm{kPa})$ & 1.9 \\
\hline RTFO aged residual & $G^{*} / \sin \delta$ at $76 \mathrm{C}(\mathrm{kPa})$ & 3.3 \\
\hline \multirow{3}{*}{ RTFO + PAV aged residual } & $G^{*} \sin \delta$ at $25^{\circ} \mathrm{C}(\mathrm{kPa})$ & 3650 \\
& Stiffness at $-12^{\circ} \mathrm{C}(\mathrm{MPa})$ & 285 \\
& $m$-value at $-12^{\circ} \mathrm{C}$ & 0.302 \\
\hline
\end{tabular}

program to conduct an analysis of variance (ANOVA) and Fisher's least significant difference (LSD) comparison with an $\alpha=0.05$. The ANOVA was performed first to determine whether significant differences among sample means existed. In the analyses of this study, the significance level was 0.95 , indicating that each finding had a $95 \%$ chance of being true. Upon determining that there were differences among sample means using the ANOVA, the LSD was then calculated. The LSD is defined as the observed differences between two sample means necessary to declare the corresponding population means difference. Once the LSD was calculated, all pairs of sample means were compared. If the difference between two sample means was greater than or equal to the LSD, the population means were declared to be statistically different [20].

\section{Results and Discussion}

3.1. Rotational Viscosity. Generally, the mixing temperature of the asphalt mixture is selected based on the binder viscosity, which reflects the ability for pumping and coating with aggregate in asphalt plant. Figure 5 shows the experimental values of the viscosities measured at $135^{\circ} \mathrm{C}$ and $180^{\circ} \mathrm{C}$. All binder samples exhibited relatively higher viscosity values due to the use of SBS-modified PMA binder as the base binder. Adding GTR to the base PMA binder significantly increased the binder viscosity. Also, the PG76-22 with SIS showed higher viscosities compared to the base PMA binder. The addition of SIS content of $5 \%$ is 
<smiles>CC(C)=CCC(C)(C)CC(C)(C)CC(C)(C)CC(CC(C)(C)C)c1ccccc1</smiles>

SIS

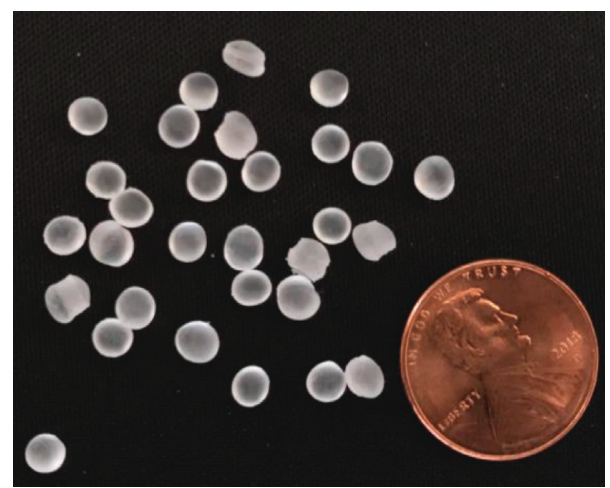

(b)

FIGURE 2: SIS (styrene-isoprene-styrene).

TABLE 2: Gradation of GTR used in this study.

\begin{tabular}{lcc}
\hline Sieve no. $(\mu \mathrm{m})$ & \multicolumn{2}{c}{ GTR } \\
& \% retained & \% cumulative retained \\
\hline $30(600)$ & 0 & 0.0 \\
$40(425)$ & 3.6 & 3.6 \\
$50(300)$ & 68.5 & 72.1 \\
$80(180)$ & 11.1 & 83.2 \\
$100(150)$ & 10.0 & 93.2 \\
$200(75)$ & 6.1 & 99.3 \\
\hline
\end{tabular}

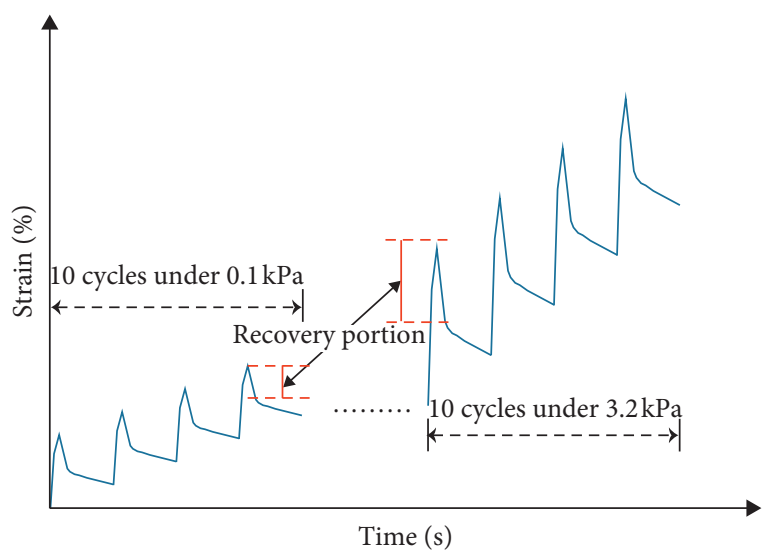

Figure 3: 10 cycles of creep and recovery at two stress levels of $0.1 \mathrm{kPa}$ and $3.2 \mathrm{kPa}$.

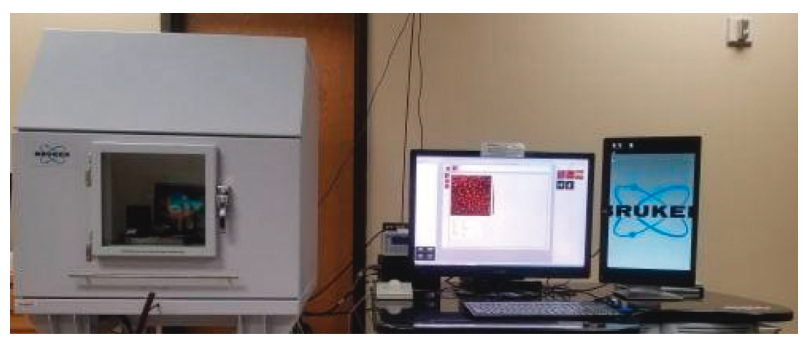

Figure 4: Atomic force microscopy (AFM).

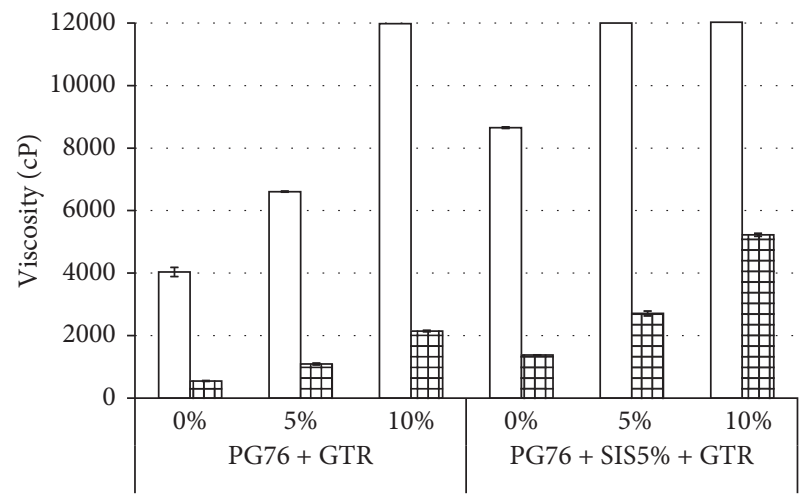

GTR content in PMA binder

$$
\begin{aligned}
& \text { ㅁ } 135^{\circ} \mathrm{C} \\
& \text { ㅂ } 180^{\circ} \mathrm{C}
\end{aligned}
$$

FIgure 5: Viscosity of the PMA binder with GTR at $135^{\circ} \mathrm{C}$ and $180^{\circ} \mathrm{C}$.

observed to have a significant contribution towards increasing the viscosity of PG 76-22. Due to the high viscosity characteristics associated with the addition of SIS, the viscosity could not be measured at $135^{\circ} \mathrm{C}$ even at $5 \%$ of GTR. Thus, all binder viscosities were also measured at $180^{\circ} \mathrm{C}$ to have comparisons and trends in viscosity values. The results at $180^{\circ} \mathrm{C}$ showed that both GTR and SIS seemed to increase the binder viscosities of PG 76-22 binder, as expected. Also, similar percentage increase of viscosity within each group (compared to the base PG 7622 and PG 76-22+SIS5\%) with the addition of GTR content (5\% and 10\%) was observed. As a result, SIS content seemed to have a significant effect on increasing the viscosity of the binder.

The statistical significance of the viscosity as a function of GTR percentages and the presence of SIS was examined, and the results are shown in Table 3 . The data demonstrate that the GTR has a significant effect on the viscosity value. The increase in viscosity is also evident with an increase in the GTR content. The addition of SIS has a significant influence on the viscosity at all GTR contents. 
TABLE 3: Statistical analysis results of the viscosity at $180^{\circ} \mathrm{C}$ as a function of addition of SIS and GTR contents $(\alpha=0.05)$.

\begin{tabular}{|c|c|c|c|c|c|c|c|}
\hline \multirow{2}{*}{$J_{\mathrm{nr}}$} & & \multicolumn{3}{|c|}{ PG76 + GTR } & \multicolumn{3}{|c|}{ PG76 + GTR + SIS5\% } \\
\hline & & $0 \%$ & $5 \%$ & $10 \%$ & $0 \%$ & $5 \%$ & $10 \%$ \\
\hline \multirow{3}{*}{ PG76 + GTR } & $0 \%$ & - & $S$ & $\mathrm{~S}$ & $\mathrm{~S}$ & $\mathrm{~S}$ & $\mathrm{~S}$ \\
\hline & $5 \%$ & & - & $S$ & $\mathrm{~S}$ & S & S \\
\hline & $10 \%$ & & & - & $S$ & S & $\mathrm{S}$ \\
\hline \multirow{3}{*}{ PG76 + GTR + SIS5\% } & $0 \%$ & & & & - & $\mathrm{S}$ & $\mathrm{S}$ \\
\hline & $5 \%$ & & & & & - & $S$ \\
\hline & $10 \%$ & & & & & & - \\
\hline
\end{tabular}

$\mathrm{N}$ : nonsignificant; S: significant.

3.2. Rutting Property. The higher $G^{*} / \sin \delta$ from the DSR test indicates that the binders are less susceptible to rutting or permanent deformation at high pavement temperatures. The $G^{*} / \sin \delta$ values of binders in the original state and after short-term aging were measured at $76^{\circ} \mathrm{C}$. The results are shown in Figure 6 . The addition of SIS resulted in increased $G^{*} / \sin \delta$ values compared to PG76 + GTR, for both aging states. In addition, the rubberized PMA binder showed the higher $G^{*} / \sin \delta$ than the control PMA binder, suggesting that the addition of SIS and GTR has a positive effect on resistance to plastic deformation. The results after RTFO showed that the $G^{*} / \sin \delta$ value increased with increasing GTR percentage, meaning that the higher the GTR content, the better the rutting resistance. In the original state, the addition of $5 \%$ and $10 \%$ GTR into PG76+SIS5\% binder exhibited approximately 12 and 11 times higher $G^{*} / \sin \delta$ values, respectively, as compared to the corresponding GTR contents in PG76 base binder. The trend is consistent after short-term aging, indicating that the use of SIS has a significant contribution to rutting resistance.

The statistical results of the $G^{*} / \sin \delta$ values are shown in Table 4 . In general, the data indicated that the addition of GTR has a significant effect on the $G^{*} / \sin \delta$ value within each aging state. Also, the difference by the presence of SIS is significant at both aging states. In both aging states, there was a significant difference in the $G^{*} / \sin \delta$ value depending on the GTR. This indicates that the effect of GTR contents is statistically significant on the rutting property. The rutting property is greatly various depending on the performance of asphalt binder which holds the interlocking of aggregate. Added GTR particle is swelled in the binder to form a viscous gel which improves binder property such as the inherent temperature susceptibility [21].

3.3. Multiple Stress Creep Recovery (MSCR) Test. The MSCR tests were conducted on the short-term aged binder to evaluate the rutting resistance of asphalt binders according to AASHTO TP 70. Figure 7 shows the variation of creep compliance at $3.2 \mathrm{kPa}$ stress level and percent recovery of the rubberized PMA binders at $76^{\circ} \mathrm{C}$. The specification of the MSCR test indicates a technological improvement to the current PG specification to better characterize the hightemperature performance properties of the asphalt binder [22]. The nonrecoverable creep compliance $J_{\text {nr }}$ represents the rutting susceptibility at high temperature for the modified binders. \%rec addresses the manifestation of the delayed

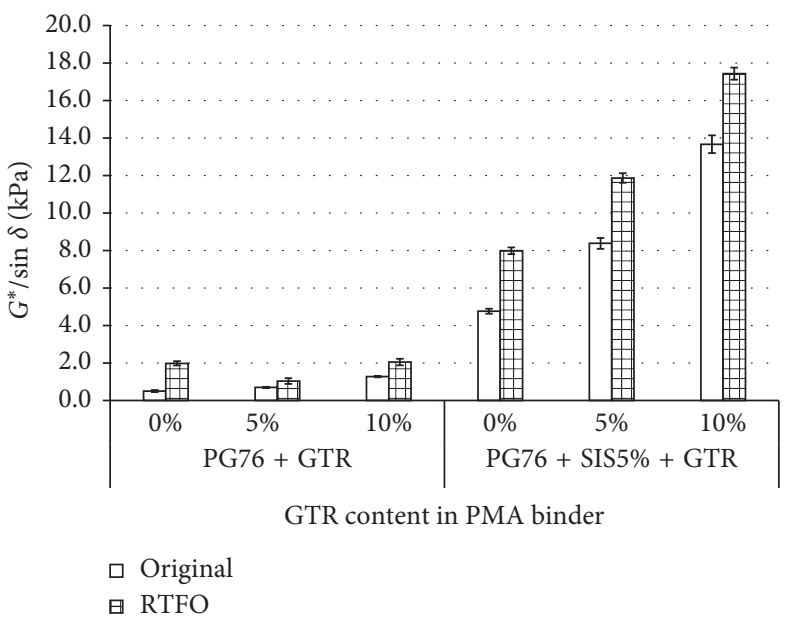

Figure 6: $G^{*} / \sin \delta$ of the PMA binders with GTR and SIS at $76^{\circ} \mathrm{C}$.

elastic response of the asphalt binder. A high delayed elastic response is an indication that the asphalt binder has a significant elastic component at the test temperature.

The addition of GTR obviously decreased the $J_{\mathrm{nr}}$ values in PMA binders as shown in Figure 7(a). With the SIS addition, $J_{\mathrm{nr}}$ values were decreased to be close to zero. It was found that GTR has less influence to decrease the $J_{\mathrm{nr}}$ values, compared with SIS modifier. Both GTR and SIS are observed to be effective to increase the \%rec values of PMA binders. The PG76 + SIS5\% containing 10\% GTR showed the lowest $J_{\mathrm{nr}}$ value and highest \%rec value as compared to the all other binders, meaning that the PG76 + SIS5\% + GTR10\% has the best rutting resistance with a highest recovery rate.

The statistical significance of the change in creep and recovery value for short-term aged binder as a function of addition of SIS and GTR contents was analyzed, and the results are shown in Table 5. The effect of GTR additives is observed to be not statistically significant when used with SIS additives. In addition, there was a significant difference in the \%rec values depending on the GTR percentage and the addition of SIS.

3.4. Fatigue Cracking Property. The product of the complex shear modulus $G^{*}$ and the sine of the phase angle $(\delta)$ is used in Superpave binder specification to help control the fatigue of asphalt pavements. Higher values of $G^{*} \sin \delta$ are considered to be undesirable in terms of fatigue cracking resistance. The $G^{*} \sin \delta$ values of the binders (RTFO + PAV 
TABLE 4: Statistical analysis results of the $G^{*} / \sin \delta$ as a function of addition of SIS and GTR contents $(\alpha=0.05)$.

\begin{tabular}{|c|c|c|c|c|c|c|c|}
\hline & & \multicolumn{3}{|c|}{ PG76 + GTR } & \multicolumn{3}{|c|}{ PG76 + GTR + SIS5\% } \\
\hline & & $0 \%$ & $5 \%$ & $10 \%$ & $0 \%$ & $5 \%$ & $10 \%$ \\
\hline \multicolumn{8}{|c|}{$G^{*} / \sin \delta$ at $76^{\circ} \mathrm{C}$ (Original) } \\
\hline & $0 \%$ & - & $\mathrm{N}$ & $\mathrm{S}$ & S & $S$ & S \\
\hline \multirow[t]{3}{*}{ PG76 + GTR } & $5 \%$ & & - & $\mathrm{S}$ & S & S & S \\
\hline & $10 \%$ & & & - & $S$ & S & $\mathrm{S}$ \\
\hline & $0 \%$ & & & & - & S & S \\
\hline \multirow[t]{2}{*}{ PG76 + GTR + SIS5\% } & $5 \%$ & & & & & - & $S$ \\
\hline & $10 \%$ & & & & & & - \\
\hline \multicolumn{8}{|c|}{$G^{*} / \sin \delta$ at $76^{\circ} \mathrm{C}(\mathrm{RTFO})$} \\
\hline & $0 \%$ & - & $\mathrm{S}$ & $\mathrm{N}$ & S & S & $\mathrm{S}$ \\
\hline \multirow[t]{3}{*}{ PG76 + GTR } & $5 \%$ & & - & $\mathrm{S}$ & S & S & S \\
\hline & $10 \%$ & & & - & $S$ & S & $\mathrm{S}$ \\
\hline & $0 \%$ & & & & - & S & S \\
\hline \multirow[t]{2}{*}{ PG76 + GTR + SIS5\% } & $5 \%$ & & & & & - & $\mathrm{S}$ \\
\hline & $10 \%$ & & & & & & - \\
\hline
\end{tabular}

N: nonsignificant; S: significant.

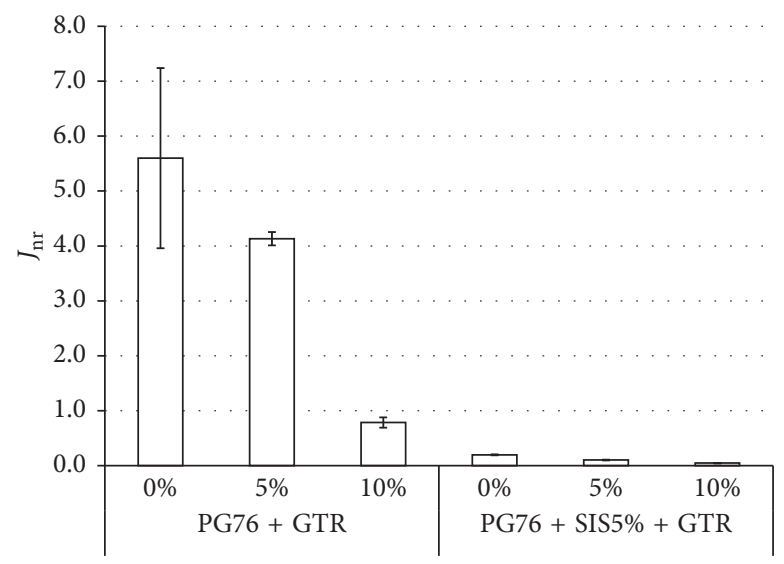

GTR content in PMA binder

(a)

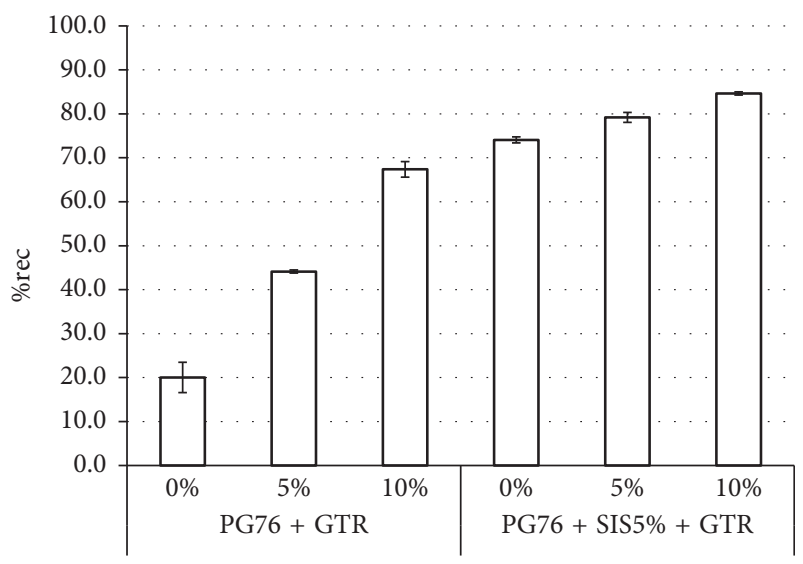

GTR content in PMA binder

(b)

FIGURE 7: Variations in creep compliance and percent recovery of the PMA binder with GTR at $76^{\circ} \mathrm{C}$ : (a) $J_{\mathrm{nr}}$ and (b) \%rec.

TABLE 5: Statistical analysis results of the MSCR as a function of addition of SIS and GTR contents $(\alpha=0.05)$.

\begin{tabular}{|c|c|c|c|c|c|c|c|}
\hline & & \multicolumn{3}{|c|}{ PG76 + GTR } & \multicolumn{3}{|c|}{ PG76 + GTR + SIS5\% } \\
\hline & & $0 \%$ & $5 \%$ & $10 \%$ & $0 \%$ & $5 \%$ & $10 \%$ \\
\hline \multicolumn{8}{|l|}{$J_{n r}$} \\
\hline & $0 \%$ & - & $\mathrm{S}$ & S & S & S & $\mathrm{S}$ \\
\hline \multirow[t]{3}{*}{ PG76 + GTR } & $5 \%$ & & - & $S$ & $S$ & $S$ & $S$ \\
\hline & $10 \%$ & & & - & $\mathrm{N}$ & $\mathrm{N}$ & $\mathrm{N}$ \\
\hline & $0 \%$ & & & & - & $\mathrm{N}$ & $\mathrm{N}$ \\
\hline \multirow[t]{2}{*}{ PG76 + GTR + SIS5\% } & $5 \%$ & & & & & - & $\mathrm{N}$ \\
\hline & $10 \%$ & & & & & & - \\
\hline \multicolumn{8}{|l|}{$\operatorname{Rev}$} \\
\hline \multirow{4}{*}{ PG76 + GTR } & $0 \%$ & - & $\mathrm{S}$ & S & S & S & S \\
\hline & $5 \%$ & & - & S & S & S & S \\
\hline & $10 \%$ & & & - & S & S & S \\
\hline & $0 \%$ & & & & - & $\mathrm{S}$ & S \\
\hline \multirow[t]{2}{*}{ PG76 + GTR + SIS5\% } & $5 \%$ & & & & & - & $\mathrm{S}$ \\
\hline & $10 \%$ & & & & & & - \\
\hline
\end{tabular}

N: nonsignificant; S: significant. 
residual) were measured using the DSR at $25^{\circ} \mathrm{C}$, and the results are illustrated in Figure 8. The base PG76 binder exhibited the highest $G^{*} \sin \delta$ value among all the PMA binders. However, GTA $10 \%$ resulted in approximately $55 \%$ decreased values compared to GTA0\% in both PMA binders, indicating that the GTR has a positive effect on the resistance of fatigue cracking. The effect of GTR which improves the cracking resistance is consistent with previous studies $[23,24]$. On average, the $G^{*} \sin \delta$ values of PG + SIS $5 \%+$ GTR are decreased by approximately $20 \%$ compared to the corresponding binders without SIS.

The statistical significance of the change in the $G^{*} \sin \delta$ value as a function of the addition of SIS and GTR contents was examined, and the results are shown in Table 6. The results indicated that GTR contents have a significant effect on the $G^{*} \sin \delta$ value of PMA binders. Also, the presence of SIS in the PMA binder is found to cause a different result in the $G^{*} \sin \delta$ value at the $5 \%$ level.

3.5. Thermal Cracking Property. Superpave asphalt binder specification includes values up to $300 \mathrm{MPa}$ for creep stiffness, and the reduction in stiffness diminishes the tensile stress of the asphalt binder for less possibility of thermal cracking. The effect of GTR and SIS contents on the lowtemperature cracking properties of the PMA binders was observed by performing the BBR test on the long-term aged condition at $-12^{\circ} \mathrm{C}$. The stiffness and $m$-value of rubberized PMA binders with or without SIS were measured, and the results are illustrated in Figures 9 and 10, respectively. Generally, the results are consistent as described in the fatigue cracking results. The addition of GTR to the PG76 binder and PG76 + SIS5\% binder resulted in a decrease in the stiffness values of PMA binders. PG76 + SIS5\% + GTR binders showed approximately $10 \%$ lower stiffness values compared to the PG76 + GTR. The effect of improving the cracking properties by the addition of SIS is not as obvious as the result of rutting resistance evaluated by DSR and MSCR. However, all the binders satisfied the maximum stiffness of $300 \mathrm{MPa}$ and the minimum $m$-value of 0.3 , except for $m$-value of PG76 + SIS5\% + GTR0\%.

The statistical significance of the change in the stiffness as a function of the addition of SIS and GTR contents was analyzed, and the results are shown in Table 7 . The data show that there was a statistically significant difference in the stiffness values depending on the GTR content, indicating that the increase in GTR content resulted in a substantial change in stiffness values. The statistical results of the $m$ values are shown in Table 8. It was found that the data indicate an insignificant difference in the $m$-value depending on the addition of SIS and GTR contents.

3.6. Morphology. Figure 11 shows topographical images and the phase images of long-term aged rubberized PMA binders without SIS. In Figure 11(a), the topographic image consists of microstructure which is a sequence of hills and valleys or a succession of pale and dark lines. It is designated as a "bee-like" structure or "bee" shape. According to the previous research, bee shapes are due to the presence of microcrystalline wax and

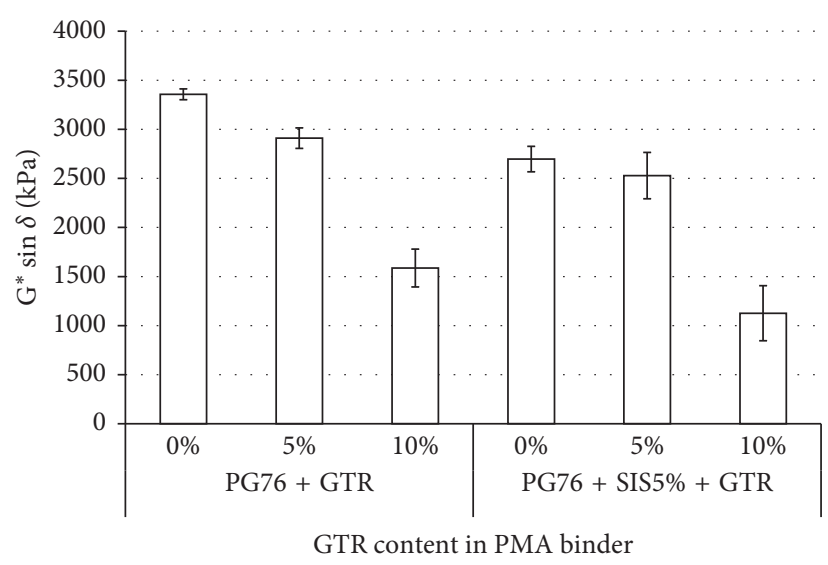

FIgUre 8: $G^{*} \sin \delta$ at $25^{\circ} \mathrm{C}$ of the PMA binders with GTR and SIS.

waxy molecules in the binder [25-28]. Also, the size and number of bee shapes are considered to reflect the cracking property. Generally, the cracking performances are evaluated by measuring $G^{*} \sin \delta$ and stiffness values. However, the microstructural analysis through AFM images is expected to provide insight of the cracking performance [29]. As shown in topographical images (Figures 11(a), 11(c), and 11(e)), the addition of GTR content decreases the size of the bee structure and this reduction of area of bee shapes expected to increase the cracking resistance of the binder. Further clear images of bee shape can be shown in the phase images (Figures 11(b), 11(d), and 11(f)). The phase image of PG76+GTR10\% ( $f)$ showed that the size of bee structure reduced more and it indicates that PG76+GTR10\% results in superior cracking resistance with smaller size of bee shape based on the previous study [28] which concluded that the smaller size and less number of bee shape have better cracking resistance. It is observed to be consistent with the cracking properties measured by DSR and BBR tests.

PG76 + SIS5\% + GTR binder samples were scanned with AFM after long-term aging. Topographical images and phase images of aged samples are shown in Figure 12. The similar trend was appeared on the images. The size of bee shape decreased with increasing GTR content. In topographical image of GTR0\% (Figure 12(a)), there are several circular black spots. Even though the black color has faded, it is still observed in Figure 12(c), PG76 + SIS5\% + GTR5\%. The circular shape is considered as a unique feature of SIS. However, it is getting disappeared by the addition of GTR. Regardless of these circular shapes, GTR10\% showed smaller size and less number of bee shapes which showed the best cracking resistance with lowest stiffness value.

\section{Summary and Conclusions}

In this study, GTR and SIS modifiers were incorporated to improve the performance properties of SBS-modified PG 76-22 binder. Rubberized PMA binders with or without SIS were manufactured using the wet process and artificially short-term and long-term aged in the laboratory. A series of Superpave binder tests were accomplished using the rotational viscometer, the DSR, and the BBR to evaluate various properties (viscosity, 
TABLE 6: Statistical analysis results of the $G^{*} \sin \delta$ as a function of addition of SIS and GTR contents $(\alpha=0.05)$.

\begin{tabular}{|c|c|c|c|c|c|c|c|}
\hline \multirow{2}{*}{\multicolumn{2}{|c|}{$G^{*} \sin \delta$ at $25^{\circ} \mathrm{C}(\mathrm{RTFO}+\mathrm{PAV})$}} & \multicolumn{3}{|c|}{ PG76 + GTR } & \multicolumn{3}{|c|}{ PG76 + GTR + SIS5\% } \\
\hline & & $0 \%$ & $5 \%$ & $10 \%$ & $0 \%$ & $5 \%$ & $10 \%$ \\
\hline \multirow{3}{*}{ PG76 + GTR } & $0 \%$ & - & $\mathrm{S}$ & $\mathrm{S}$ & $\mathrm{S}$ & $\mathrm{S}$ & $\mathrm{S}$ \\
\hline & $5 \%$ & & - & $S$ & $\mathrm{~N}$ & S & S \\
\hline & $10 \%$ & & & - & $\mathrm{S}$ & $\mathrm{S}$ & $\mathrm{S}$ \\
\hline \multirow{3}{*}{ PG76 + GTR + SIS5\% } & $0 \%$ & & & & - & $\mathrm{S}$ & S \\
\hline & $5 \%$ & & & & & - & $\mathrm{S}$ \\
\hline & $10 \%$ & & & & & & - \\
\hline
\end{tabular}

N: nonsignificant; S: significant.

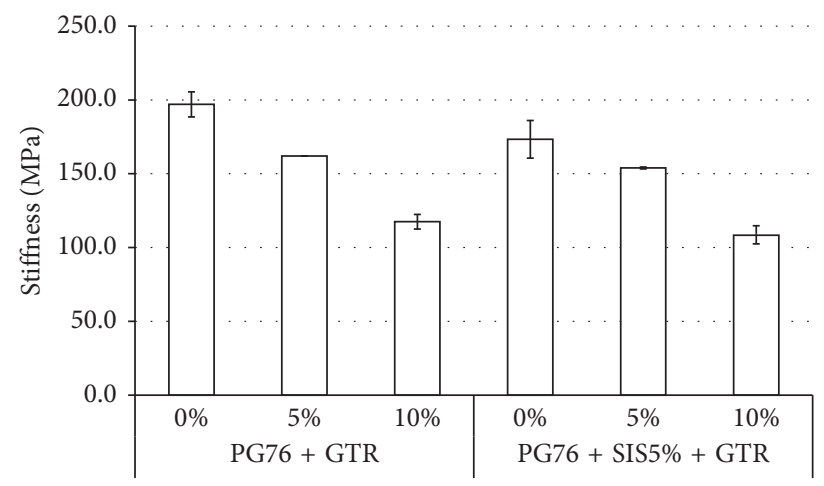

GTR content in PMA binder

Figure 9: Stiffness at $-12^{\circ} \mathrm{C}$ of the PMA binders with GTR and SIS.

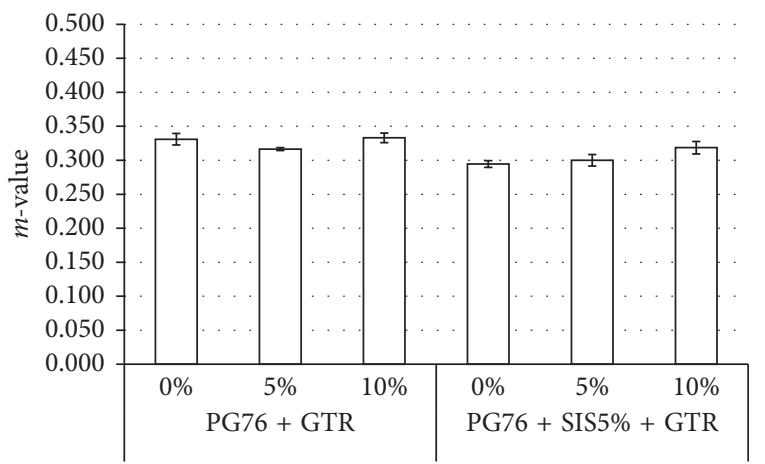

GTR content in PMA binder

FIgure 10: $m$-value at $-12^{\circ} \mathrm{C}$ of the PMA binders with GTR and SIS.

TABLE 7: Statistical analysis results of the stiffness as a function of addition of SIS and GTR contents $(\alpha=0.05)$.

\begin{tabular}{|c|c|c|c|c|c|c|c|}
\hline \multirow{2}{*}{ Stiffness } & & \multicolumn{3}{|c|}{ PG76 + GTR } & \multicolumn{3}{|c|}{ PG76 + GTR + SIS5\% } \\
\hline & & $0 \%$ & $5 \%$ & $10 \%$ & $0 \%$ & $5 \%$ & $10 \%$ \\
\hline \multirow{3}{*}{ PG76 + GTR } & $0 \%$ & - & $S$ & $\mathrm{~S}$ & $\mathrm{~S}$ & $S$ & $S$ \\
\hline & $5 \%$ & & - & $\mathrm{S}$ & $\mathrm{N}$ & $\mathrm{N}$ & $\mathrm{S}$ \\
\hline & $10 \%$ & & & - & $\mathrm{S}$ & $\mathrm{S}$ & $\mathrm{N}$ \\
\hline \multirow{3}{*}{ PG76 + GTR + SIS5\% } & $0 \%$ & & & & - & $\mathrm{S}$ & $\mathrm{S}$ \\
\hline & $5 \%$ & & & & & - & $\mathrm{S}$ \\
\hline & $10 \%$ & & & & & & - \\
\hline
\end{tabular}

N: nonsignificant; S: significant. 
TABLE 8: Statistical analysis results of the $m$-value as a function of addition of SIS and GTR contents $(\alpha=0.05)$.

\begin{tabular}{|c|c|c|c|c|c|c|c|}
\hline \multirow{2}{*}{$m$-value } & & \multicolumn{3}{|c|}{ PG76 + GTR } & \multicolumn{3}{|c|}{ PG76 + GTR + SIS5\% } \\
\hline & & $0 \%$ & $5 \%$ & $10 \%$ & $0 \%$ & $5 \%$ & $10 \%$ \\
\hline \multirow{3}{*}{ PG76 + GTR } & $0 \%$ & - & $\mathrm{N}$ & $\mathrm{N}$ & $\mathrm{S}$ & $\mathrm{S}$ & $\overline{\mathrm{N}}$ \\
\hline & $5 \%$ & & - & $\mathrm{N}$ & S & $\mathrm{N}$ & $\mathrm{N}$ \\
\hline & $10 \%$ & & & - & $\mathrm{S}$ & $S$ & $\mathrm{~N}$ \\
\hline \multirow{3}{*}{ PG76 + GTR + SIS5\% } & $0 \%$ & & & & - & $\mathrm{N}$ & $\mathrm{S}$ \\
\hline & $5 \%$ & & & & & - & S \\
\hline & $10 \%$ & & & & & & - \\
\hline
\end{tabular}

$\mathrm{N}$ : nonsignificant; S: significant.

$49.0 \mathrm{~nm}$

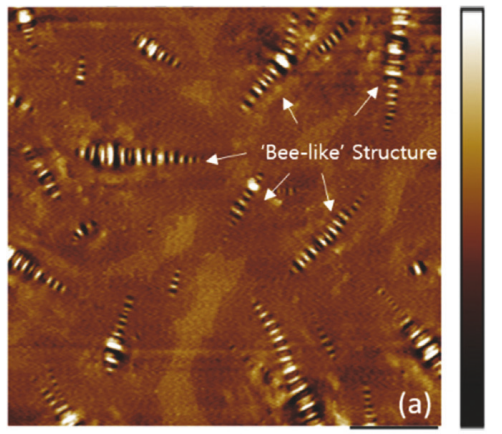

$4.0 \mu \mathrm{m}$

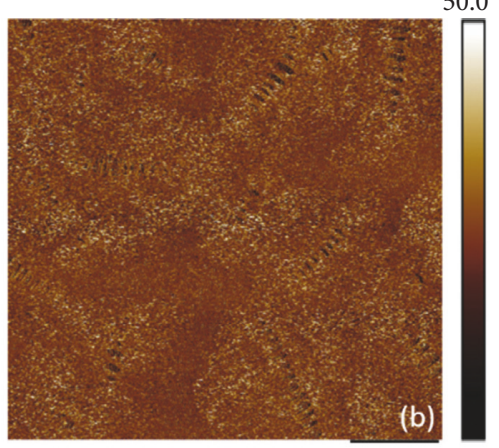

$4.0 \mu \mathrm{m}$ $50.0^{\circ}$

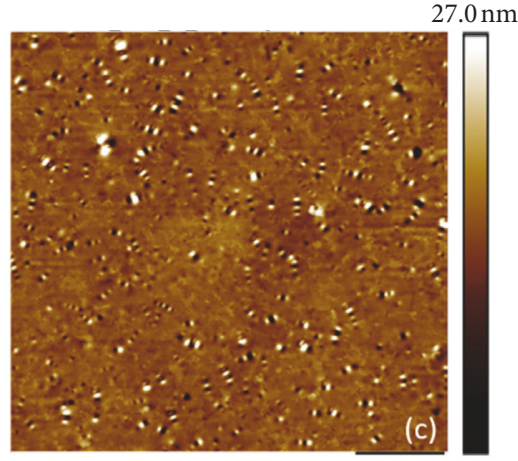

$4.0 \mu \mathrm{m}$

$15.0^{\circ}$

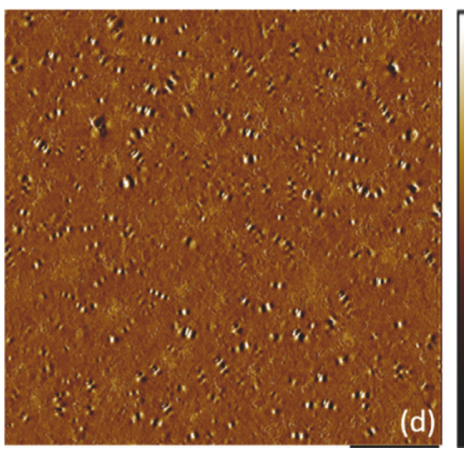

$4.0 \mu \mathrm{m}$

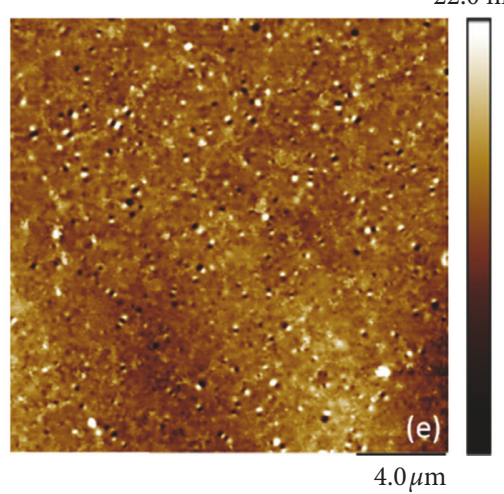

$22.0 \mathrm{~nm}$

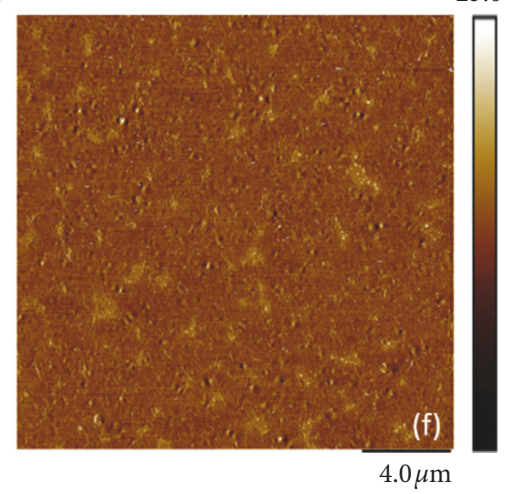

FIgURE 11: AFM images of rubberized PMA binders without SIS. (a) Topographical image of GTR0\%. (b) Phase image of GTR0\%. (c) Topographical image of GTR5\%. (d) Phase image of GTR5\%. (e) Topographical image of GTR10\%. (f) Phase image of GTR10\%.

rutting, fatigue cracking, and low-temperature cracking) of the binders. MSCR test was also conducted to deeply investigate the rutting properties. In addition, the microstructural analysis using AFM images was performed to evaluate the cracking performance considering the bee shape on the binder surface. Based on the result of these tests, the following conclusions were drawn for the materials used in this study:

(1) Both GTR and SIS modifiers resulted in increasing the viscosity of PMA binders, as expected.

(2) According to the DSR test results, the use of SIS significantly improved the rutting resistance (measured by $G^{*} / \sin \delta$ ).

(3) In general, it is shown that the addition of SIS and GTR is effective in improving the rutting behaviors in accordance with the results of the MSCR test.
(4) From the DSR test at $25^{\circ} \mathrm{C}$, the addition of GTR and SIS has a positive effect on the fatigue cracking resistance (measured by $G^{*} \sin \delta$ ).

(5) In the BBR test, the PMA binder including 10\% GTR and $5 \%$ SIS has the lowest stiffness value.

(6) Morphology images by AFM explain the influence of SIS on improving cracking resistance. The size and number of bee shapes are found to be decreased by the addition of GTR and SIS.

(7) Generally, the addition of SIS and GTR into SBSmodified PG 76-22 binder upgraded the binder properties for both rutting and cracking performances.

(8) For future study, SIS and GTR additives can be evaluated with asphalt mixtures to verify the positive effects on performance properties. 

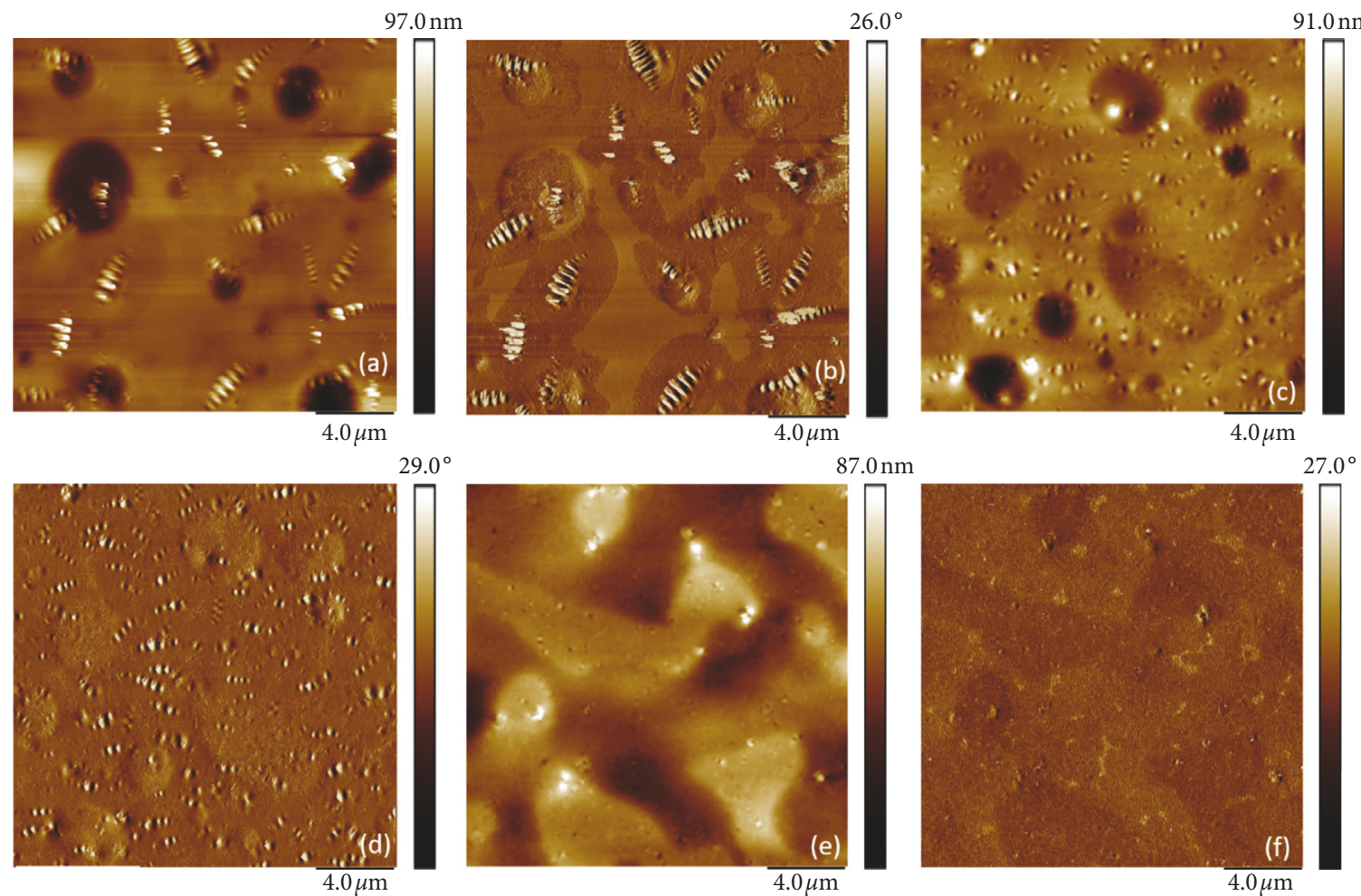

$87.0 \mathrm{~nm}$
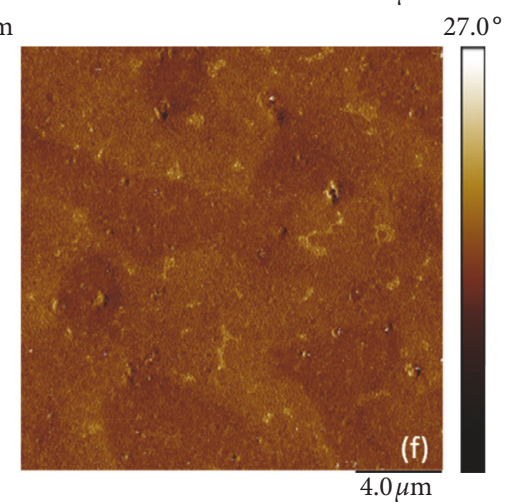

FIGURE 12: AFM images of rubberized PMA binders with SIS. (a) Topographical image of GTR0\%. (b) Phase image of GTR0\%. (c) Topographical image of GTR5\%. (d) Phase image of GTR5\%. (e) Topographical image of GTR10\%. (f) Phase image of GTR10\%.

\section{Data Availability}

The data used to support the findings of this study are available from the corresponding author upon request.

\section{Conflicts of Interest}

The authors declare that they have no conflicts of interest.

\section{Acknowledgments}

This research was supported by the Research Grant from KICT through the Korea Agency for Infrastructure Technology Advancement funded by the Ministry of Land, Infrastructure and Transport of the Korean government (Project no. 18TBIP-C125410-02).

\section{References}

[1] Y. Becker, M. P. Mendez, and Y. Rodriguez, "Polymer modified asphalt," Vision Tecnologica, vol. 9, no. 1, 2000.

[2] A. Adedeji, T. Grünfelder, F. S. Bates, C. W. Macosko, M. Stroup-Gardiner, and D. E. Newcomb, "Asphalt modified by SBS triblock copolymer: structures and properties," Polymer Engineering \& Science, vol. 36, no. 12, pp. 1707-1723, 1996.

[3] R. Roque, B. Birgisson, C. Drakos, and G. Sholar, Guidelines for Use of Modified Binders (No. UF Project No. 4910-4504964-12), The National Academies of Sciencess, Engineering, and Medicine, Washington, DC, USA, 2005.
[4] US Tire Manufacturers Association, 2017 U.S. Scrap Tire Management Summary, U.S. Tire Manufacturers Association, Washington, DC, USA, 2018.

[5] S.-C. Huang and A. T. Pauli, "Particle size effect of crumb rubber on rheology and morphology of asphalt binders with long-term aging," Road Materials and Pavement Design, vol. 9, no. 1, pp. 73-95, 2008.

[6] R. G. Hicks, D. Cheng, T. Duffy, and T. Teesdale, Evaluation of Rubberized Asphalt Terminal Blends and a Preliminary Study on Warm Mix, 2010.

[7] B. Huang, L. Mohammad, P. Graves, and C. Abadie, "Louisiana experience with crumb rubber-modified hot-mix asphalt pavement," Transportation Research Record: Journal of the Transportation Research Board, vol. 1789, no. 1, pp. 1-13, 2002.

[8] G. B. Way, "OGFC meets CRM-where the rubber meets the rubber-12 years of the durable success," in Proceedings of the Asphalt Conference, Atlanta, Georgia, 1998.

[9] S. K. Palit, K. S. Reddy, and B. B. Pandey, "Laboratory evaluation of crumb rubber modified asphalt mixes," Journal of Materials in Civil Engineering, vol. 16, no. 1, pp. 45-53, 2004.

[10] J. Shen and S. Amirkhanian, "The influence of crumb rubber modifier (CRM) microstructures on the high temperature properties of CRM binders," International Journal of Pavement Engineering, vol. 6, no. 4, pp. 265-271, 2005.

[11] S. J. Lee, Characterization of recycled aged crm binders, Ph.D. thesis, Clemson University, Clemson, SC, USA, 2007.

[12] B. E. Ruth and R. Roque, "Crumb rubber modifier (CRM) in asphalt pavements," in Transportation Congress, Volumes 1 and 2: Civil Engineers-Key to the World's Infrastructure, pp. 768-785, ASCE, Reston, VA, USA, 1995. 
[13] F. Xiao, P. E. Wenbin Zhao, and S. N. Amirkhanian, "Fatigue behavior of rubberized asphalt concrete mixtures containing warm asphalt additives," Construction and Building Materials, vol. 23, no. 10, pp. 3144-3151, 2009.

[14] H. H. Kim and S.-J. Lee, "Effect of crumb rubber on viscosity of rubberized asphalt binders containing wax additives," Construction and Building Materials, vol. 95, pp. 65-73, 2015.

[15] M. F. Azizian, P. O. Nelson, P. Thayumanavan, and K. J. Williamson, "Environmental impact of highway construction and repair materials on surface and ground waters," Waste Management, vol. 23, no. 8, pp. 719-728, 2003.

[16] L. Xiang, J. Cheng, and G. Que, "Microstructure and performance of crumb rubber modified asphalt," Construction and Building Materials, vol. 23, no. 12, pp. 3586-3590, 2009.

[17] P. Lin, W. Huang, N. Tang, and F. Xiao, "Performance characteristics of Terminal Blend rubberized asphalt with SBS and polyphosphoric acid," Construction and Building Materials, vol. 141, pp. 171-182, 2017.

[18] F. Zhang, C. Hu, and Y. Zhang, "The research for SIS compound modified asphalt," Materials Chemistry and Physics, vol. 205, pp. 44-54, 2018.

[19] H. U. Bahia, "Critical evaluation of asphalt modification using strategic highway research program concepts," Transportation Research Record, vol. 1488, pp. 82-88, 1995.

[20] R. L. Ott and M. T. Longnecker, An Introduction to Statistical Methods and Data Analysis, Cengage Learning, Boston, MA, USA, 2008.

[21] S.-J. Lee, C. K. Akisetty, and S. N. Amirkhanian, "The effect of crumb rubber modifier (CRM) on the performance properties of rubberized binders in HMA pavements," Construction and Building Materials, vol. 22, no. 7, pp. 1368-1376, 2008.

[22] A. W. Ali, H. H. Kim, M. Mazumder, M. S. Lee, and S. J. Lee, "Multiple Stress Creep Recovery (MSCR) characterization of polymer modified asphalt binder containing wax additives," International Journal of Pavement Research and Technology, vol. 11, pp. 774-788, 2018.

[23] H. Kim, K.-D. Jeong, M. S. Lee, and S.-J. Lee, "Performance properties of CRM binders with wax warm additives," Construction and Building Materials, vol. 66, pp. 356-360, 2014.

[24] H. H. Kim and S.-J. Lee, "Evaluation of rubber influence on cracking resistance of crumb rubber modified binders with wax additives," Canadian Journal of Civil Engineering, vol. 43, no. 4, pp. 326-333, 2016.

[25] A. Schmets, N. Kringos, T. Pauli, P. Redelius, and T. Scarpas, "On the existence of wax-induced phase separation in bitumen," International Journal of Pavement Engineering, vol. 11, no. 6, pp. 555-563, 2010.

[26] A. T. Pauli, R. W. Grimes, A. G. Beemer, T. F. Turner, and J. F. Branthaver, "Morphology of asphalts, asphalt fractions and model wax-doped asphalts studied by atomic force microscopy," International Journal of Pavement Engineering, vol. 12, no. 4, pp. 291-309, 2011.

[27] P. K. Das, N. Kringos, V. Wallqvist, and B. Birgisson, "Micromechanical investigation of phase separation in bitumen by combining atomic force microscopy with differential scanning calorimetry results," Road Materials and Pavement Design, vol. 14, no. 1, pp. 25-37, 2013.

[28] H. H. Kim, M. Mazumder, and S.-J. Lee, "Micromorphology and rheology of warm binders depending on aging," Journal of Materials in Civil Engineering, vol. 29, no. 11, article 4017226, 2017a.

[29] H. H. Kim, M. Mazumder, A. Torres, S. J. Lee, and M. S. Lee, "Characterization of CRM binders with wax additives using an atomic force microscopy (AFM) and an optical microscopy," Advances in Civil Engineering Materials, vol. 6, no. 1, pp. 504-525, 2017 b. 


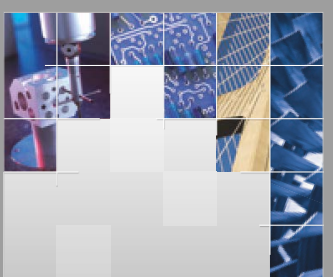

\section{Enfincering}
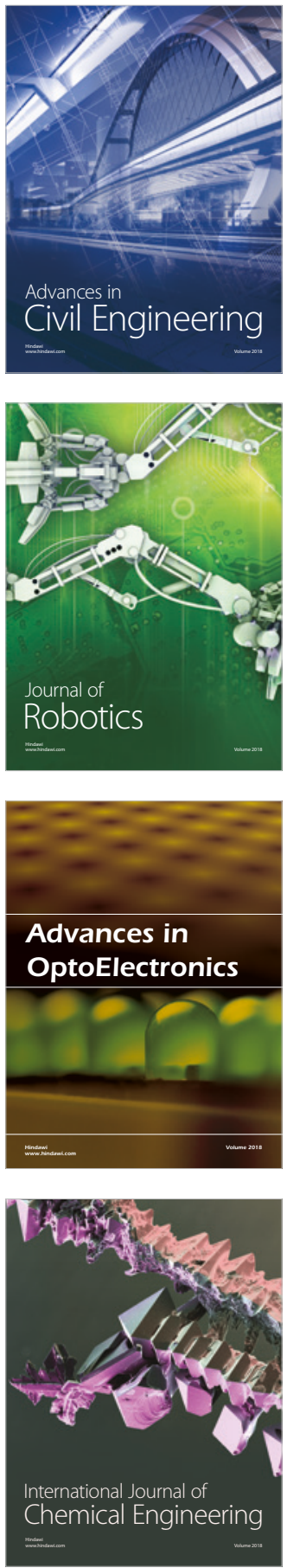

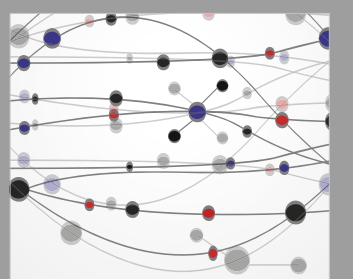

\section{Rotating \\ Machinery}

The Scientific World Journal

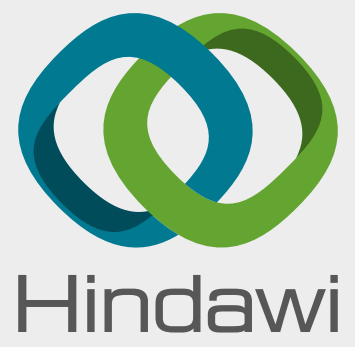

Submit your manuscripts at

www.hindawi.com
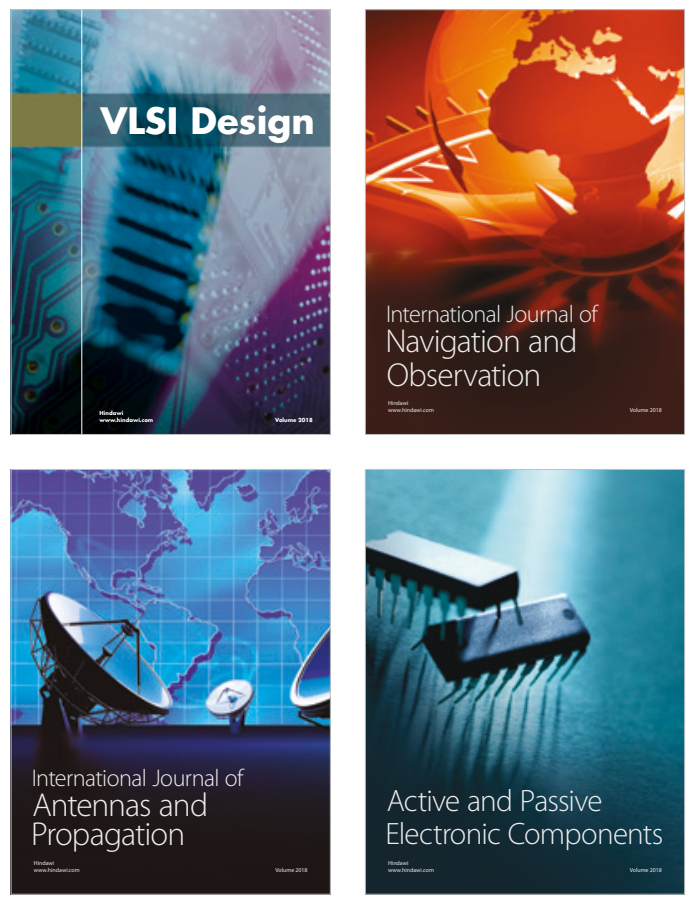
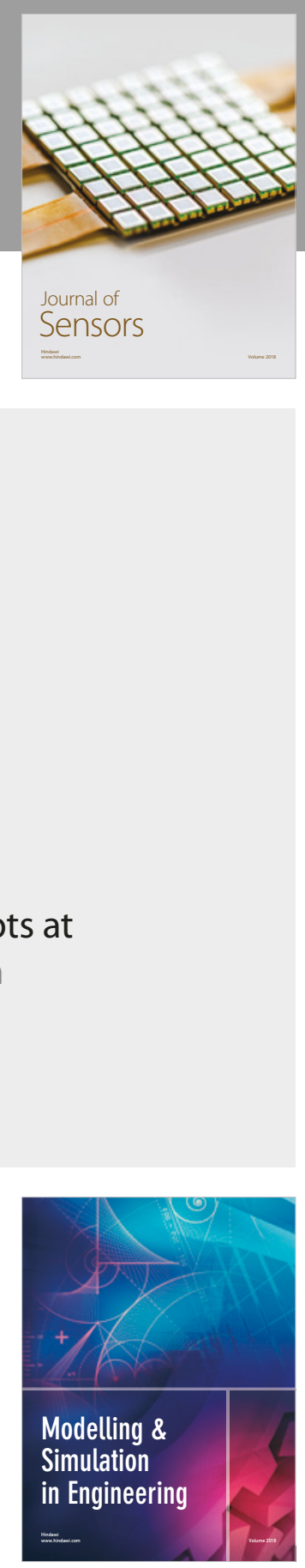

\section{Advances \\ Multimedia}
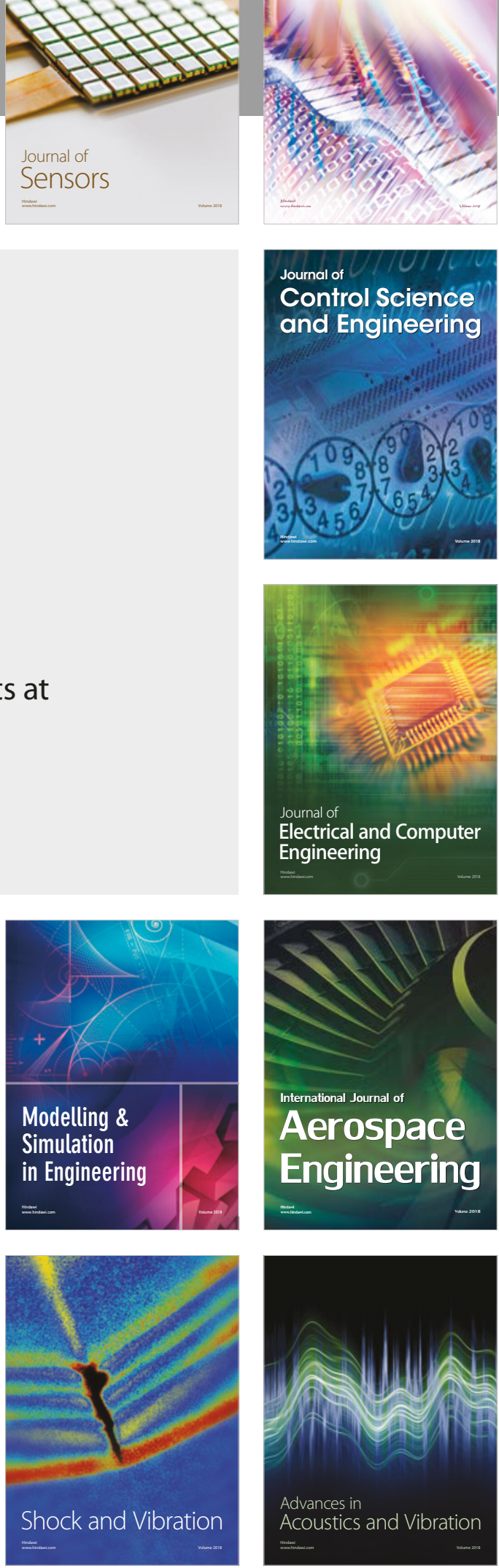